\title{
The Spread of Policy Diffusion Studies: A Systematic Review and Meta-Analysis, 1990- 2018
}

\author{
Daniel J. Mallinson, Ph.D. \\ Assistant Professor of Public Policy and Administration \\ Penn State Harrisburg \\ United States of America \\ mallinson@psu.edu \\ ORCID: 0000-0002-8094-6685
}

Research on how policies diffuse throughout the American federal system is robust and vast, but there has yet to be a systematic accounting for its results. Using a systematic review and metaanalysis, this study presents the most comprehensive analysis to date of how policy innovation flows state-to-state and the average effects of commonly used variables in the study of policy diffusion (e.g., neighbor adoptions, ideological distance between states, legislative professionalism, and more). Additionally, heterogeneity in these effects is examined across regulatory, morality, and governance policy types. The study not only reveals what we know about policy diffusion after 30 years of quantitative analysis, it identifies several correctable gaps in the literature. The results not only support the efforts to expand diffusion research to large-n analyses, but they also reveal additional benefits of small-n event history studies for the progressive advancement of this important research program.

Acknowledgements: The author would like to thank Luke Yingling, Nick Turnier, and Tom Delany for their help in coding and checking the database and Christopher Ojeda and Julie Pacheco for their comments and suggestions on the manuscript. Earlier versions of these results were presented at the 2018 State Politics and Policy Conference in State College, PA and the 2014 American Political Science Association Annual Meeting in Washington, DC. This research has been funded by Stockton University's Provost Faculty Opportunity Funds and Research \& Professional Development funds. All errors in the manuscript and database are my own. Reproduction scripts and data can be found at https://doi.org/10.7910/DVN/NASPUC 
Hundreds of articles have tackled the fundamental question of why innovative policies spread. Innovations are any policy idea that has not been previously adopted by a government unit, be it a city, municipality, subnational, or national government (Walker 1969). Policy diffusion occurs when the adoption of these innovations by different governmental jurisdictions is not spontaneous and independent, but interdependent through the spreading of policy, political, and normative information as well as competitive pressures between political units (Volden et al. 2008; Adam 2016). Regardless of whether research focuses on diffusion among the American states or across international borders, scholars seek to understand why ideas spread and what motivates a state or country to take them up. The early core of this work was largely performed in the American context (e.g., Walker 1969; Savage 1978), however a cross-national literature has also blossomed (e.g., Gilardi 2012; Gilardi and Wasserfallen 2019). Examining spatial patterns of diffusion has helped researchers wrestle with how policy and political information shape adoption decisions and how institutional structures affect the flow of that information. Thus, policy diffusion remains a vital research program with broad interest within political science.

Since 1990, much of this research program has been built using single policy event history (EHA) studies. Alas, there is at least a decade-long concern about the diminishing returns of this prevailing methodology (Boehmke 2009). Recent data accumulation efforts, such as the State Policy Innovation and Diffusion database (Boehmke et al. 2019), push diffusion research towards larger-N studies, as do new methods that extend the boundaries of how diffusion dynamics are tested (Butler et al. 2017; Linder et al. 2018). These developments are pushing diffusion research in a new direction, but there has been no systematic accounting of the numerous single policy studies that build on Berry and Berry's general theory of policy 
diffusion. Such research accumulation is important for evaluating what has been learned, what remains to be tested, and how even single policy studies can remain useful in the future. I take up this task by systematically reviewing the literature that uses EHA modeling and using metaanalysis to synthesize its key results.

In addressing this lacuna, the present study systematically gathered the entire collection of single and multiple policy EHA diffusion studies published from 1990 to 2018. It is important to note that in doing so this review is on the body of work using EHA methodology, not the entirety of diffusion research. The purpose for this narrowing is to allow for a meta-analysis of the results. The resulting effort yielded 183 qualifying articles containing 507 policy adoption models. From these models, this study seeks to answer the following questions:

1. What is the degree of policy and temporal coverage of these studies? Relatedly, what topics and time periods are missing that may bias our understanding of diffusion?

2. How general is Berry and Berry's theoretical model? How do diffusion dynamics differ for regulatory, morality, and governance policies?

The remainder of this study briefly reviews the importance of policy diffusion research, presents the methodology used to search for and synthesize relevant literature, and discusses two sets of findings: (1) gaps and biases resulting from convenience sampling in these studies and (2) the general effects of neighbor state adoptions, ideological learning, legislative professionalism, citizen/government ideology, slack resources, and federal influence on policy adoption writ large and heterogeneity in those effects across regulatory, morality, and governance policy types. It concludes with a discussion of how diffusion research can move forward. 


\section{Diffusion Theory and the Case-by-Case Approach}

Policy diffusion research is invested in understanding interdependencies among political units and how those interactions shape public policy. Whether the units are national, subnational, or local governments, diffusion is thought to be a function of the motivations of key political actors within government, the amount of resources available to the units for overcoming obstacles to adoption, the interaction with other policies already adopted by the units, and external influences (Berry and Berry 2018). This is referred to by Berry and Berry (2018) as the Unified Model of Policy Diffusion, meaning it unifies previously disparate models of adoption based on either internal characteristics of the state or external influences. Within the American federal system, states are typically the locus of study, with external influences being horizontal (i.e., other states) and vertical (i.e., the federal government and local governments).

Research on policy diffusion emerged from studies of localities and states, with early scholarship documenting commonalities between text in adopted bills as well as patterns of innovativeness across the states (McCoy 1940; Walker 1969; Gray 1973). After this early work, researchers turned to discretely studying internal and external predictors of policy adoption. Since Berry and Berry (1990) first presented a unified approach using EHA, diffusion researchers have sought to test the model and heterogeneity in its effects across numerous policies. At the same time, researchers have also worked to understand both the macro- and micro-level dynamics that shape the diffusion process more generally. At the macro-level, researchers have studied patterns of adoption using the temporal ordering and geographic distribution of state adoptions. At the micro-level, research has focused on the causal mechanisms tied to the actions of legislators, legislative staff, interest groups, policy entrepreneurs, and other actors (e.g., Butler et al. 2017). 
A core assumption of diffusion research is that states are not simply spontaneously adopting innovations, but they are in fact gathering information or are influenced by each other. To that end, scholars identify observable macro-level patterns that suggest the presence of policy learning, political learning, interstate competition, federal coercion, and social contagion in the spread of particular innovations (Pacheco 2012; Shipan and Volden 2008). Three of the most widely tested explanations of diffusion patterns include the adoption of an innovation by contiguous neighbors or states in an immediate region, adoption by ideologically similar/distant states, and some form of federal intervention (Berry and Berry 1990; Grossback et al. 2004; Nicholson-Crotty 2009; Welch and Thompson 1980). While these variables can be measured and modeled using EHA, the conclusions drawn from such studies are not always clear. For example, it is difficult to parse out whether neighbor adoptions are the result of learning or competition (Berry and Baybeck 2005). Furthermore, formal theory and simulation evidence reveal that analyses of neighboring state influence can sometimes produce false positives when states simultaneously adopt innovations to solve a problem. Such a pattern gives the appearance of neighboring state influence, but is not reflective of diffusion because the innovations were independent and occurred without any cross-border information exchange (Volden et al. 2008; Adam 2016).

Another strand of diffusion research focuses more on the internal resources and obstacles to diffusion. For example, slack resources allow states to be more innovative (Boehmke and Skinner 2012a), more professionalized legislatures have greater capacity for innovation (Squire 2012), initiatives can pave the way for and legitimize new ideas (Hannah and Mallinson 2018), and liberal and Democratic states are expected to be more innovative (Matisoff 2008). Divided government, on the other hand, can stifle innovation via gridlock (Sellers 2017). Many of the 
internal determinants speak to how differences in institutional design across the states shape innovation adoption.

Berry and Berry's unified approach using EHA is excellent at identifying heterogeneity in the effects of both internal and external determinants of diffusion across different policies. This is because each model can include variables applicable to the specific context of the policy being studied. What is not clear from so many individual studies, however, is the broader patterns of commonly included variables like neighbor adoptions, ideology, and more. Research synthesis is necessary to provide this bigger picture. While narrative reviews of the policy diffusion research program exist (e.g., Karch 2007), no one has yet systematically evaluated the breadth and findings of these studies.

\section{Search Methodology}

Compared to fields like health science, systematic reviews are not as commonplace in political science (e.g., Lau et al. 2007; Costa 2017). Those that are published lack a consistent procedural framework, so this study relied upon the Preferred Reporting Items for Systematic Reviews and Meta-Analyses (PRISMA) standards from the health sciences (Moher et al. 2009; Liberati et al. 2009). The process occurred in five steps: (1) Define the problem (rationale and objectives); (2) determine inclusion/exclusion criteria; (3) conduct the literature search; (4) record data from each study; (5) analyze results. Each step is thoroughly discussed in the supplemental information. ${ }^{1}$ A shorter discussion is included here to provide context for the review and meta-analysis.

Studies were included using the following criteria: (1) published after Berry and Berry (1990); (2) model policy adoption, not other dependent variables; (3) adoptions occurred in the

\footnotetext{
${ }^{1}$ The search database, article database, reproduction data, and code are available on https://doi.org/10.7910/DVN/NASPUC.
} 
American states ${ }^{2}$; and (4) used a monadic or dyadic EHA approach. This is important for the meta-analysis, as all models use the same type of outcome and study design. Searches were conducted using Web of Science on Berry and Berry (1990), Google Scholar (search terms "policy diffusion" and "berry and berry"), the partial listing of EHA studies in Graham et al. (2013) and a list provided in Berry and Berry (2018). ${ }^{3}$ Figure 1 presents a flow diagram for the literature search (Moher et al. 2009). A total of 2,749 articles were identified from the different sources, 419 articles passed an initial screening of abstracts, and 185 articles met the full inclusion criteria. Most exclusions resulted either from covering international diffusion or only having only a passing reference to policy diffusion in the article. While Berry and Berry are widely cited, not all the citing articles are diffusion studies. The fact that nearly 3,000 articles resulted from the wide search process is indicative of how broadly innovation theory is cited within many subfields of political science and outside disciplines. A total of 507 EHA model results were extracted from the included articles.

Table 1 displays the study characteristics gathered from each article. Sixteen aspects of each study/model were measured under four broad categories: the article, data, included geographic measures, and modeling choices. Additionally, coefficients, standard errors, and measures of statistical significance (p-values, t-statistics, and more) were extracted and recorded for every variable included in each of the 507 models. $^{4}$

\footnotetext{
${ }^{2}$ I focus this review exclusively on the United States for several reasons. First, there is a tight core of research within the American context (Graham et al. 2013). Second, there is a robust linkage between the study of policy diffusion within the United States and federalism studies. Third, within-country diffusion has different dynamics than cross-country diffusion. For example, the international literature suggests that coercion is not a meaningful mechanism of diffusion (Maggetti and Gilardi 2016), which may make sense for the international system, but does not for diffusion within a country (Balla and Deering 2015). Finally, a common dependent variable is necessary for the meta-analysis.

${ }^{3}$ My corpus of literature differs from the 700 articles identified by Graham et al. (2013) Their review included not only the international diffusion literature, but also the separate literature on policy transfer.

${ }^{4}$ One limitation of the resulting database is that some authors choose to footnote null results instead of reporting them fully. It is possible that there is bias towards finding significant effects in the present study. To minimize this,
} 


\section{Figure 1. Flow Diagram for the Literature Search}

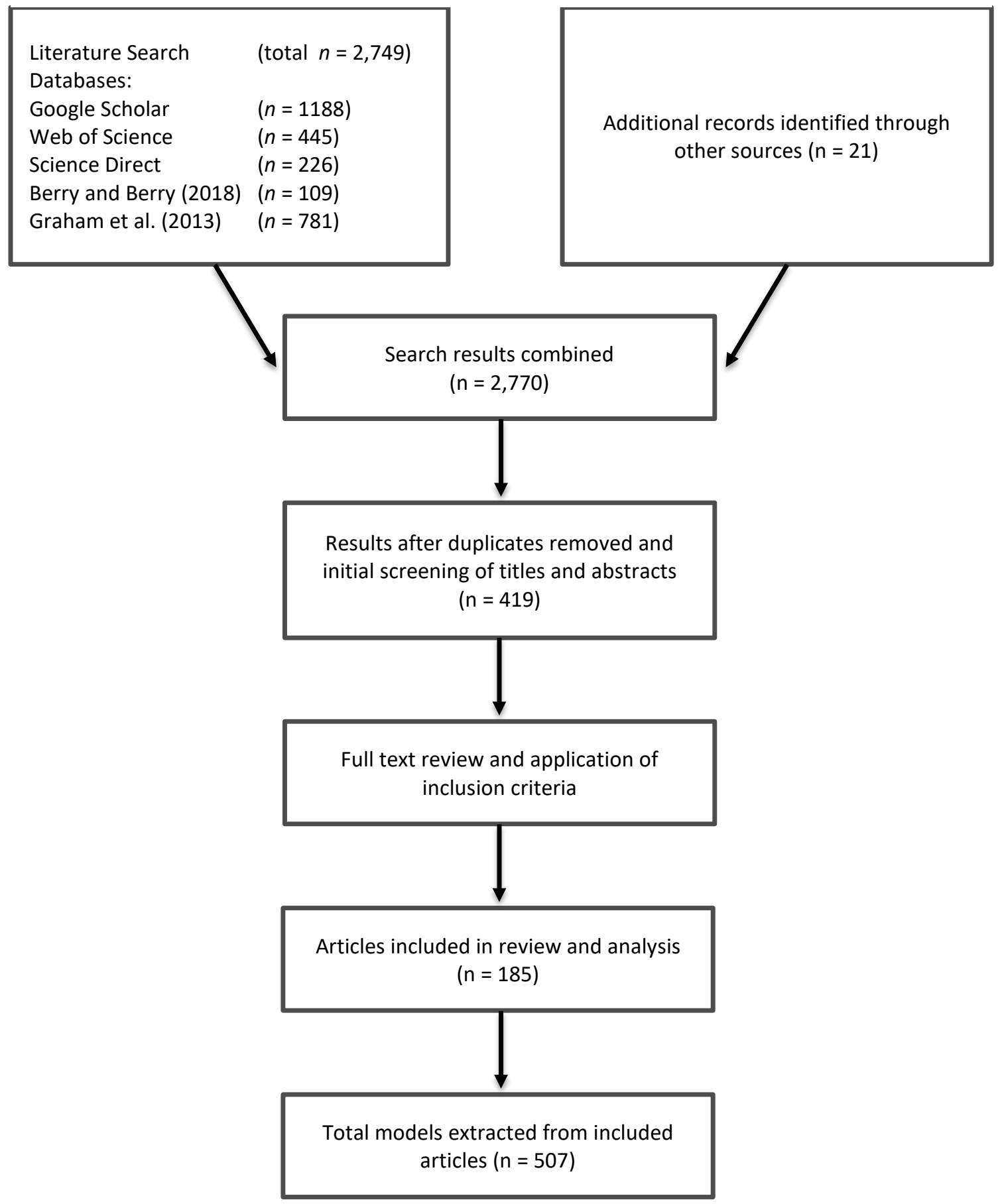

every effort was made to include all available results in the database, including accessing appendices and online supplemental files. 
Table 1: Data collected from included diffusion articles

\begin{tabular}{l|l|l|l}
\hline \multicolumn{1}{c}{ Article } & \multicolumn{1}{c}{ Data } & \multicolumn{1}{c}{ Geography } & Estimation Strategy \\
\hline Citation & Major topic code* & Neighbor measure included? & Model type \\
Information & Sub-topic code* & Type of neighbor measure & Effects type \\
& Included state count & Other geographic measures? & Duration method \\
Political & Excluded states & Description of other & \\
Science & DC included? & geographic variables & \\
Journal & First adoption year & & \\
Indicator & Last adoption year & & \\
\hline
\end{tabular}

* These are the major and sub-topic codes modified to fit state politics for the Pennsylvania Policy Database Project (McLaughlin et al. 2010). They were used instead of the codes from the larger Policy Agendas Project because they are adapted specifically for coding state policies.

\section{Review and Meta-Analysis Methodology}

Reviewing the assembled literature proceeds in two parts: (1) an evaluation of the policy and temporal scope of this research and (2) a meta-analysis of key results from the diffusion models. Systemic Review of Diffusion Studies

The first part of the evaluation examines how the study of diffusion has evolved since Berry and Berry (1990). I first focus on the policy and temporal coverage of the models. I then review the theoretically meaningful clusters of variables, some of which are further analyzed in the meta-analysis below, to assess their prevalence across diffusion models. Such clusters include neighbor adoptions, ideological learning, federal influence, political institutions, legislative professionalism, slack resources, and government/citizen ideology. Finally, I consider the inclusion of context-specific variables which often speak directly to the innovation at hand but rarely generalize across policy domains.

The temporal and subject focus of this analysis provides a better understanding of which policies are amply studied and which have received little attention. A continual concern in diffusion research is its reliance on convenience sampling (Savage 1978; Walker 1973). Some 
have argued that the accumulation of adoption data can help to overcome this problem (Boehmke and Skinner 2012b; Boehmke et al. 2019), while others have used smaller sets of population data (Nicholson-Crotty et al. 2014). As will be discussed later, even databases like SPID suffer from convenience sampling bias. This study directly quantifies the potential for bias among EHA studies.

\section{Meta-Analysis of Diffusion Models}

The second part of the analysis includes a meta-analysis of key diffusion findings. To some extent, each published adoption study is at least implicitly connected to Berry and Berry's (1990, 2018) unified model of diffusion. Not all studies, however, purport to advance diffusion theory directly. Some wish to explain the spread of a single innovation for an audience that cares about that specific policy. Further, many studies are novel because the dynamics of their policy's spread differ from others. Thus, the aim of this section is twofold. First, to identify generalized effects across the diverse array of included policies, and second, to examine heterogeneity in those effects across three types of policies: regulatory, morality, and governance (Boushey 2010).

This research synthesis addresses key spatial (geographic proximity to and ideological distance from prior adopters), internal (political and demographic), slack resource (financial and legislative) and federal influence determinants of adoption. Specifically, eleven predictors were chosen for analysis: prior adoption by neighbors, ideological distance, federal intervention (policy adoption or implementation), per capita income, legislative professionalism, citizen and government liberalism, initiative availability, Democratic and Republican control of government, and divided government. These predictors were selected both because they are considered theoretically important to policy diffusion and because they tend to be measured similarly across 
studies. It is important to note what is not included in this meta-analysis. Foremost are the pervasive contextual variables. It is difficult to assess their general effects given that the expectation for their impact on the likelihood of adoption is highly dependent on the given policy. Additional research of these variables could certainly be done using the database of effects produced by this study.

In addition to estimating combined effects across all the studies, meta-analyses are performed for three different types of policies: regulatory, morality, and Governance. These are the same types that Boushey (2010) used to analyze variation in the speed of diffusion. Regulatory policies are those that provide "economic, environmental, or professional regulation" (Boushey 2010: 20). Morality policies address social regulation. These include policies such as capital punishment, abortion restrictions, gay marriage, and more (Mooney and Schuldt 2008). Finally, governance policies "modify the behavior of the public sector and officials" (Tolbert 2002: 80). Examples of governance policies include changes to voting, performance budgeting, adoption of the Missouri Plan, and more. In total, there are 261 models of policies categorized as regulatory, 216 morality, and 43 governance.

Random effects models were used for the meta-analyses due to the assumption that the true effect of each variable can vary from study to study based on the characteristics of the policy and time period studied (Schwarzer et al. 2015). The combined effects reported herein are thus the mean of a distribution of true population effects. Furthermore, model results are weighted by their sample size. This way, a study like Kreitzer (2015) that pools policies has more influence on the estimation of the general effects than one based on a single policy. The Paul and Mandel method was used for estimating $\tau^{2}$ (the variance between studies) because of its utility for dichotomous outcome data (Veroniki et al. 2016). Additionally, the Knapp-Hartung-Sidik- 
Jonkman adjustment was used, which results in more conservative confidence intervals (Hartung and Knapp 2001; Sidik and Jonkman 2002). All analyses were done in R (Viechtbauer 2010).

\section{Diffusion Literature Results}

\section{Policy Coverage}

Figure 2 displays a count of the single-policy models ( $\mathrm{n}=507$ models) by their major topic codes. ${ }^{5}$ What is most immediately clear from the graph is the degree of under-coverage in some policy domains. For instance, there are no models that represent local government and technology policy. This means that policies like special purpose districts, property tax relief, restrictions on local government debt, telephone and telecommunication regulations, broadcast industry regulations, and computers and computer security are not represented in diffusion research. Each is an area where states have been active over the past 50 years. Additionally, there are few studies on agricultural, social welfare, transportation, environment, housing, and commerce policies.

Why is underrepresentation of such policies important? Many of these domains have lower salience and higher complexity, which diffuse differently than simpler and controversial policies (Nicholson-Crotty 2009; Mallinson 2016). Missing them could bias the general effects we are able to estimate from the extant research. Furthermore, they are areas in which states are quite active and we do not know how well diffusion theory holds among policies in these domains. Additionally, there is no sense as to whether expectations regarding policy learning, competition, and more are appropriate for policies targeted at local governments. This seems like

\footnotetext{
${ }^{5}$ Note that there are no major topic codes 11, 22, or 23 in the Policy Agendas Project codebook. McLaughlin et al. (2010) added major topic 24 to account for Local Government and Governance. Major code 9 is not included because this data collection started prior to the 2015 codebook update that added it. For consistency sake, the 2011 codebook was used in each update of the database of studies.
} 
a particularly problematic lacuna given the rise of, and concern over, state preemption of local government (Riverstone-Newell 2017). It is also possible, of course, that policies in these areas did not diffuse sufficiently. Even if that is the case, additional research is necessary to empirically verify that and explore why certain policies do not diffuse.

Among the well-trod policy domains are health, law, administrative policies, and civil rights and liberties. Law and health make intuitive sense, as these represent either changes to the criminal justice system or efforts to address public health challenges. Both areas are important responsibilities for state governments. The large number of studies in the administrative policies category, however, is the result of research that recycles Berry and Berry's original lottery model. Administrative policies are likely to encompass a fair proportion of state legislation, given that these laws most often deal with the conduct of state government. Thus, while this category appears to be well attended, the large set of lottery studies obfuscates a lack of coverage of an important component of state lawmaking.

The high degree of coverage for civil rights legislation is due to a focus on morality policies like abortion (Allen et al. 2004), the death penalty (Mooney and Lee 2000), and gay marriage bans (Haider-Markel 2001), among some diffusion researchers. These issues provide a useful line of inquiry for identifying whether the same policy diffusion predictors apply to these controversial policies. Morality policies have also been a hot topic for several decades due to scholarly debate over the culture wars in America (Layman and Green 2006), and thus attract more scholarly interest. That said, they profess to diffuse differently than other policies (Mooney 2001), and thus their overrepresentation again biases our understanding of the general model of policy diffusion. 


\section{Figure 2. Count of major topics for each included model}

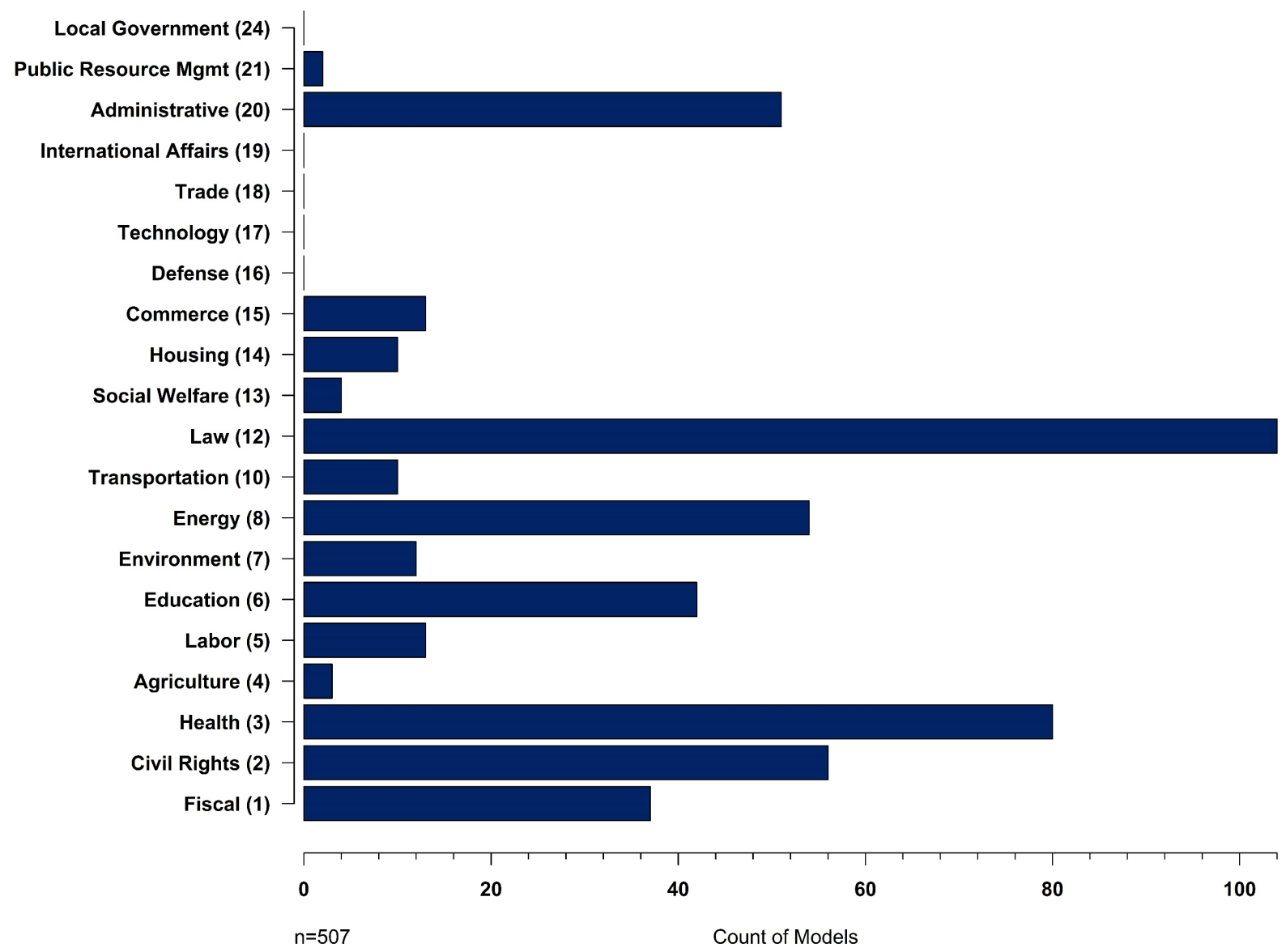

\section{Temporal Coverage}

Figure 3 displays the temporal coverage of the included diffusion research in two ways.

Figure $3 \mathrm{a}$ is a histogram of every year observed in 501 models of policy diffusion with each bar representing a single year. ${ }^{6}$ The black vertical lines in 3 a delineate each decade. Figure 3 b shows the specific year ranges of each of the 501 models arranged from bottom to top by order of the first adoption year. Figure $3 \mathrm{~b}$ shows that most of the included studies capture adoptions occurring after 1960 (the red dashed line). There is very little coverage before that. Figure $3 b$ also illustrates the substantial variation in the length of time measured by each model. Figure $3 \mathrm{a}$

\footnotetext{
${ }^{6}$ Six of the models included in the dataset came from articles that did not clearly demarcate the first and last observed adoption years.
} 
demonstrates that existing diffusion research best explains diffusion between roughly 1970 and 2010.

There is data available for the period preceding 1960 from Walker's (1969) early study. His dataset included adoptions from 1812 through 1966. Furthermore, SPID reaches back to 1692. Thus, there are now opportunities for examining diffusion patterns earlier than 1960 . The challenge, however, is measuring relevant covariates prior to that date. Even the large Correlates of State Policy dataset (Jordan and Grossman 2017) is limited in its inclusion of variables before 1960 because it is dependent on measurement by the original authors of each measure. For example, Berry et al.'s (1998) citizen and elite ideology scores are commonly used to account for state liberalism in adoption models. Unfortunately, this measure only goes back to 1960 . Thus, diffusion researchers are often limited to studying innovations that spread after 1960 or else they must locate other proxies for important diffusion determinants. 
Figure 3. Temporal Coverage of All Recorded Diffusion Models

(a)

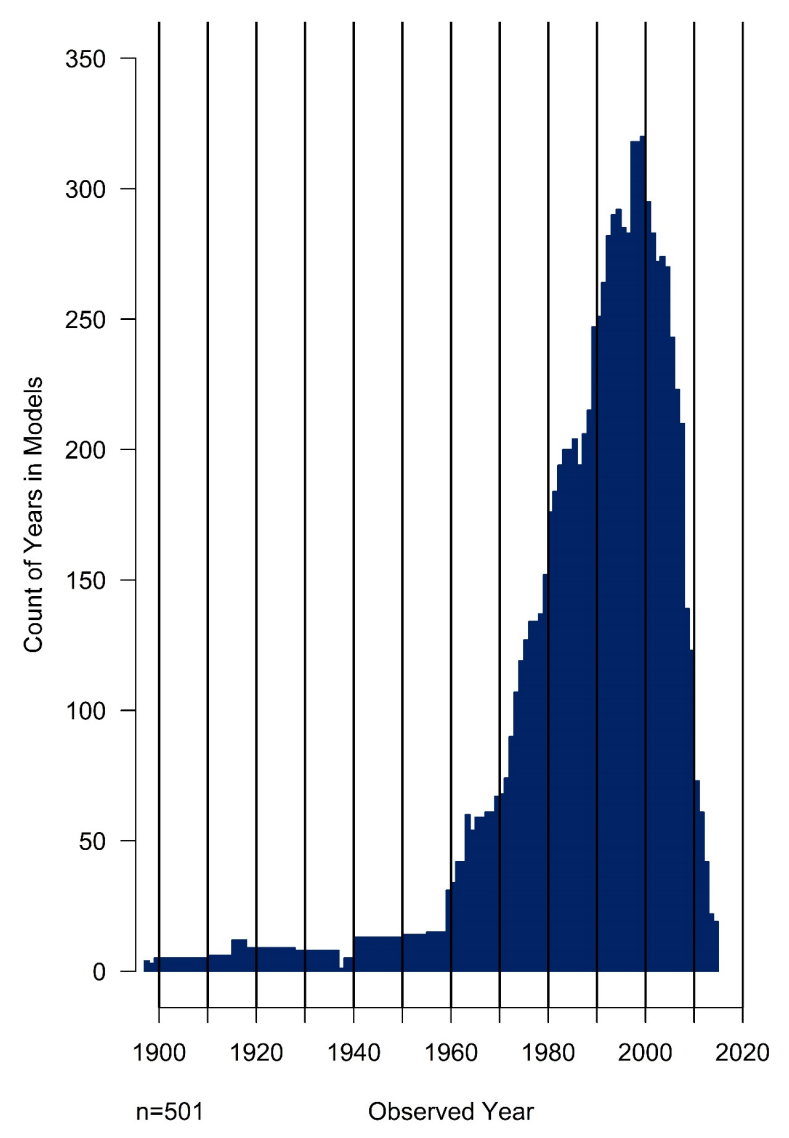

(b)

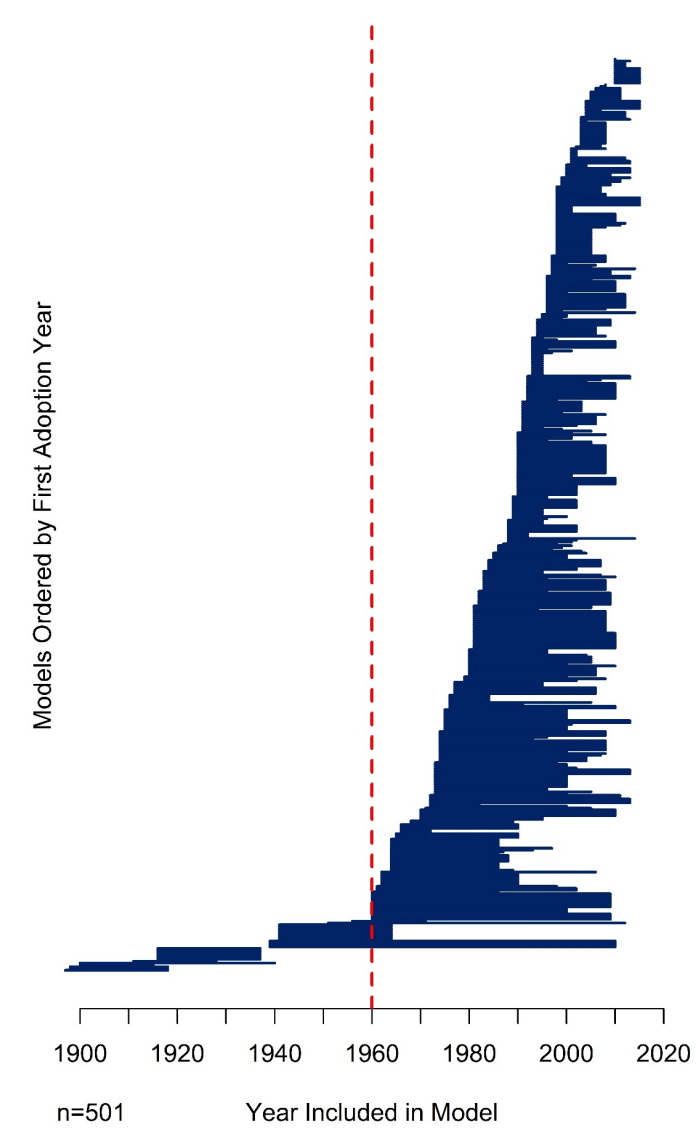

\section{Inclusion of Key Covariates}

Table 2 displays the percentage of studies that included and excluded variables that are important for diffusion theory. It is immediately apparent that contextual measures are the most prevalent in these models. A full 91 percent of the models included in this analysis used contextual covariates that apply narrowly to the innovations at hand. 


\section{Table 2: Percentage of Models That Include Key Predictors of Diffusion}

\begin{tabular}{|c|c|}
\hline Predictor(s) & Percent Included \\
\hline Contextual measure $^{\dagger}$ & 91 percent \\
\hline Other political measure $^{\dagger}$ & 82 percent \\
\hline Demographic measure $^{\dagger}$ & 76 percent \\
\hline Previous neighbor adoption & 73 percent \\
\hline Slack resources $^{\dagger}$ & 69 percent \\
\hline Ideology (Liberalism) & 60 percent \\
\hline Other geographic measure $^{\dagger}$ & 27 percent \\
\hline Legislative professionalism & 25 percent \\
\hline Federal Influence & 5 percent \\
\hline
\end{tabular}

Turning to covariates that are expected to have an impact on the diffusion process more generally, it is encouraging that close to or over 70 percent of the included models capture at least one slack resource (69 percent), at least one political measure other than liberalism or legislative professionalism ( 82 percent), or a measure of previous adoption by the state's neighbors (73 percent). A supermajority of models also includes some measure of in-state demographics (76 percent). Granted, there is a high degree of heterogeneity in the operationalization of variables within each of these categories. Even for single concepts like ideology (liberalism), the concept is not measured identically in all studies.

One political predictor that is consistently measured across policies is Squire's (2017) legislative professionalism. While this measure captures legislative capacity and is available for the time span covered by most of these studies, it was included in only 25 percent of the models. Likewise, citizen or government ideology is most often measured using Berry et al.'s (1998) liberalism scales, but they are more widely incorporated than legislative professionalism, with 60 percent of studies including some measure of within-state ideology. Finally, only 5 percent of studies include a measure of federal involvement in the dissemination of a policy. On one hand, 
this reflects the fact that direct federal intervention is not relevant for every policy and often comes after a policy has already begun spreading through the states. On the other hand, even federal issue attention has at least some influence on state policy activity (Baumgartner et al. 2009; Karch 2012), though implicit federal influence is rarely captured in these models. It is to the more commonly measured, and theoretically important, variables that we now turn for the meta-analysis.

\section{Meta-Analysis Results}

Table 3 displays the results of a simple vote count method of accumulating the results across the diffusion models. The results from each study are partitioned based on whether the resultant effect was positive and statistically significant $(p<0.05)$, negative and statistically significant $(p<0.05)$, or positive or negative, but not statistically significant $(p \geq 0.05)$. Variables with clear support in either a positive or negative direction are bolded. The total number of coefficients for each variable is also included so that the percentages have more meaning. It is worth noting that every predictor has statistically significant effects in both the positive and negative directions, except for divided government. Neighbor adoptions, federal intervention, and the presence of a direct initiative are the only variables with substantially more positive than negative effects. The significant effects for slack resources and liberalism are split evenly between positive and negative. Finally, legislative professionalism exhibits more negative effects than positive. This pattern of results demonstrates the diversity in findings that result from the fractured study of policy diffusion. Of perhaps even greater importance, is the fact that a majority of all five effects are not significant across the models. 
Table 3: Summary of effect direction for key diffusion predictors

\begin{tabular}{|c|c|c|c|c|c|}
\hline Variable & $\begin{array}{l}\text { Significant*, } \\
\text { Positive }\end{array}$ & $\begin{array}{c}\text { Not } \\
\text { Significant, } \\
\text { Positive }\end{array}$ & $\begin{array}{c}\text { Significant, } \\
\text { Negative }\end{array}$ & $\begin{array}{c}\text { Not } \\
\text { Significant, } \\
\text { Negative }\end{array}$ & $\begin{array}{l}\text { Number of } \\
\text { Coefficients }\end{array}$ \\
\hline Neighbor Adoption & 41 percent & 32 percent & 4 percent & 22 percent & 389 \\
\hline $\begin{array}{l}\text { Ideological } \\
\text { Distance }\end{array}$ & 5 percent & 30 percent & 61 percent & 5 percent & 44 \\
\hline $\begin{array}{l}\text { Federal } \\
\text { Intervention }\end{array}$ & 39 percent & 24 percent & 13 percent & 24 percent & 38 \\
\hline Per Capita Income & 22 percent & 42 percent & 9 percent & 24 percent & 193 \\
\hline $\begin{array}{l}\text { Legislative } \\
\text { Professionalism }\end{array}$ & 13 percent & 36 percent & 11 percent & 40 percent & 131 \\
\hline Citizen Liberalism & 29 percent & 36 percent & 15 percent & 20 percent & 160 \\
\hline $\begin{array}{l}\text { Government } \\
\text { Liberalism }\end{array}$ & 26 percent & 38 percent & 13 percent & 18 percent & 91 \\
\hline Initiative Available & 12 percent & 70 percent & 6 percent & 12 percent & 33 \\
\hline $\begin{array}{l}\text { Democratic Control } \\
\text { of Government }\end{array}$ & 23 percent & 26 percent & 14 percent & 37 percent & 57 \\
\hline $\begin{array}{l}\text { Republican Control } \\
\text { of Government }\end{array}$ & 13 percent & 39 percent & 18 percent & 31 percent & 95 \\
\hline $\begin{array}{l}\text { Divided } \\
\text { Government }\end{array}$ & 0 percent & 32 percent & 29 percent & 39 percent & 66 \\
\hline
\end{tabular}

The vote count procedure provides initial evidence for heterogeneity in diffusion findings and potential general effects. The next step is to properly weight the results for the different sample size of each study and account for variability in the estimated effects when estimating a general effect (Schwarzer et al. 2015). Table 4 presents the meta-analysis results for all of the models, which in some cases substantiate Table 3. Supporting policy diffusion theory, neighbor adoptions tend to have a positive effect on innovation adoption, whereas ideological distance from past adopters suppresses the likelihood of adoption. This substantiates the notion that both political and policy learning occurs during the diffusion process. Also having the direct initiative available to citizens increases the likelihood that a state will adopt an innovation and the presence of divided government reduces the likelihood of adoption. Notably, the results suggest 
that states are less likely to innovate when Republicans control government. Government liberalism also has a dampening effect on innovation. There is no evidence of general effects for federal intervention, income, legislative professionalism, citizen liberalism, and Democratic control of government.

Table 4. Meta-Analysis Results for Key Diffusion Predictors

\begin{tabular}{lccc}
\hline \hline Variable & Odds Ratio & $\boldsymbol{\tau}^{2}$ & $\mathbf{Q}$ \\
\hline Neighbor Adoptions & $1.595^{*}$ & 2.126 & $11362^{*}$ \\
& {$[1.309,1.943]$} & & $(326)$ \\
Ideological Distance & $0.988^{*}$ & 0.0004 & $492^{*}$ \\
& {$[0.980,0.999]$} & & $(37)$ \\
Federal Intervention & 1.003 & 0.106 & $138^{*}$ \\
& {$[0.875,1.151]$} & & $(31)$ \\
Income & 0.992 & 0.106 & $769^{*}$ \\
& {$[0.9281 .061]$} & & $(123)$ \\
Legislative Professionalism & 0.837 & 0.707 & $10319^{*}$ \\
& {$[0.691,1.014]$} & & $(123)$ \\
Citizen Liberalism & 1.006 & 0.007 & $1662^{*}$ \\
& {$[0.990,1.022]$} & & $(134)$ \\
Government Liberalism & $1.008^{*}$ & 0.001 & $349^{*}$ \\
Initiative Available & $\{1.001,1.015]$ & & $(80)$ \\
& $1.075^{*}$ & 0.004 & 28 \\
Democratic Control & {$[1.000,1.155]$} & & $(27)$ \\
Republican Control & 1.059 & 0.043 & $76^{*}$ \\
& {$[0.942,1.191]$} & & $(35)$ \\
Divided Government & $0.819^{*}$ & 0.138 & $233^{*}$ \\
& {$[0.726,0.924]$} & & $(63)$ \\
$* p<0.05 ;$ 95\% confidence intervals in hard brackets; degrees of freedom in parentheses
\end{tabular}

\section{Effects by Policy Type}

Table 5 presents the meta-analysis results by policy type. Heterogeneity in the estimated effects is evident across the different types of policies. It is only for regulatory policies that Republican control of government slows down the spread of innovations. This makes sense as regulatory policies are those that place additional requirements or restrictions on private sector businesses (e.g., renewable portfolio standards). Further, as the liberalism of a state's citizens increases, so does the likelihood of adopting regulatory policies. Both findings comport with 
typical expectations for this type of policy. Finally, it is also only for regulatory policies that divided government slows innovation adoption. It is notable that eternal influences like neighbor adoptions, ideological distance, and federal intervention show no overall effect for these types of policies. This not to say that external determinants are never a factor in regulatory policy diffusion, but there is no detectable general effect across the policies included here.

Turning to morality policy, external influences are evident with neighbor adoptions having a strong effect on the adoption of morality policies and ideological distance from past adopters serving to slow the spread of morality policy. Though learning, emulation, and competition cannot be distinguished with these measures (Berry and Baybeck 2005), it is the case that both political and policy learning/emulation/competition are occurring for morality policies (Grossback et al. 2004). Additionally, states with higher incomes are at an increased risk of adopting morality policies, though states with more professionalized legislatures are less likely to adopt them. This may in fact comport with recent research showing that less professionalized legislatures are more likely to copy policies (Jansa et al. 2019), though they are more likely to do so later in the spread of an innovation (Mallinson 2020). Further explicating this negative effect is an important future direction for diffusion research.

Finally, it is important to consider the governance policy results with appropriate caution. These types of policies are understudied, with only 43 models found by the literature search. Further, not all the variables (e.g., ideological distance, party control) are included in those models. For example, federal intervention appears to have a negative effect on governance policy adoption, however this results from only two studies on interstate compacts (Bowman and Woods 2007) and the spread of the direct initiative (Smith and Fridkin 2008). Neighbor adoptions do appear to have a positive overall effect on governance policy adoptions, suggesting 
that either policy learning or emulation are occurring. Competition is also possible but seems less plausible for these types of governance reforms. Finally, the initiative appears to have a strong positive effect, but this comes from one study of the spread of tax limitation measures (Martin 2009).

Table 5. Meta-analysis results by policy type

\begin{tabular}{lccc}
\hline \hline Variable & Regulatory & Morality & Governance \\
\hline Neighbor Adoptions & 1.144 & $2.249^{*}$ & $1.947^{*}$ \\
Ideological Distance & {$[0.988,1.324]$} & {$[1.374,3.683]$} & {$[1.128,3.359]$} \\
& 0.995 & $0.960^{*}$ & \\
Federal Intervention & {$[0.984,1.005]$} & {$[0.945,0.975]$} & \\
& 0.959 & 1.104 & $0.956^{*}$ \\
Income & {$[0.683,1.348]$} & {$[0.943,1.294]$} & {$[0.938,0.974]$} \\
& 1.096 & $1.015^{*}$ & 0.883 \\
Legislative Professionalism & {$[0.643,1.868]$} & {$[1.007,1.023]$} & {$[0.743,1.050]$} \\
& 0.967 & $0.732^{*}$ & 0.900 \\
Citizen Liberalism & {$[0.660,1.417]$} & {$[0.539,0.995]$} & {$[0.594,1.365]$} \\
& $1.037^{*}$ & 0.983 & 0.993 \\
Government Liberalism & {$[1.020,1.055]$} & {$[0.953,1.013]$} & {$[0.983,1.004]$} \\
& 1.005 & 1.008 & 1.869 \\
Initiative Available & {$[0.999,1.011]$} & {$[0.999,1.018]$} & {$[0.471,7.423]$} \\
& 0.466 & 1.070 & $3.053^{*}$ \\
Democratic Control & {$[0.121,1.796]$} & {$[0.762,1.502]$} & {$[2.370,5.259]$} \\
& 1.091 & 1.015 & \\
Republican Control & {$[0.823,1.445]$} & {$[0.774,1.329]$} & \\
& $0.676^{*}$ & 1.522 & \\
Divided Government & {$[0.563,0.812]$} & {$[1.042,2.223]$} & \\
& $0.784^{*}$ & 0.506 & 1.175 \\
\hline & {$[0.729,0.844]$} & {$[0.247,1.037]$} & {$[0.195,7.087]$} \\
\hline
\end{tabular}

$* p<0.05 ; 95 \%$ confidence intervals in hard brackets

\section{Null Results Bias}

One final analysis examines the potential for a "file drawer" problem in policy diffusion research (Franco et al. 2014). The "file drawer" problem describes the practice of researchers relegating models with null findings to the file drawer rather than sending them out for publication. Figure 4 presents four funnel plots, which are intended to convey whether there is a preponderance of statistically significant reported results. Essentially, if there is a potential publication bias problem, reported effects will cluster with positive or negative effects (in this 
case odds ratios) and low standard errors. The "funnel" of dashed lines indicates the region where effects are statistically significant $(p<0.05)$. Inside the funnel effects are significant, outside they are not. The vertical dotted line plots the overall calculated effect size.

Figures $4 \mathrm{a}$ and $4 \mathrm{~b}$ show funnel plots for neighbor adoptions and ideological distance, two important indictors of external influence. They tend to have substantial clustering near the apex and little fanning out, whereas initiative availability (Figure 4c) and Republican control of government (Figure 4d) show a better distribution of reported effects. Since researchers may view the presence of neighbor or ideological learning as evidence of diffusion when considering publication, the absence of these effects makes such diffusion studies difficult to publish (a null effect bias). Whereas, initiative availability and party control are more often control variables in diffusion models, albeit ones that are important to diffusion theory (i.e., internal determinants of adoption). This suggests that for some key variables, such as neighbor adoptions and ideological distance, there may be substantial reporting bias in the results of this meta-analysis. 
Figure 4. Funnel Plots for Neighbor Adoptions, Ideological Distance, Initiative Availability, and Republican Control of Government

(a) Neighbor Adoptions

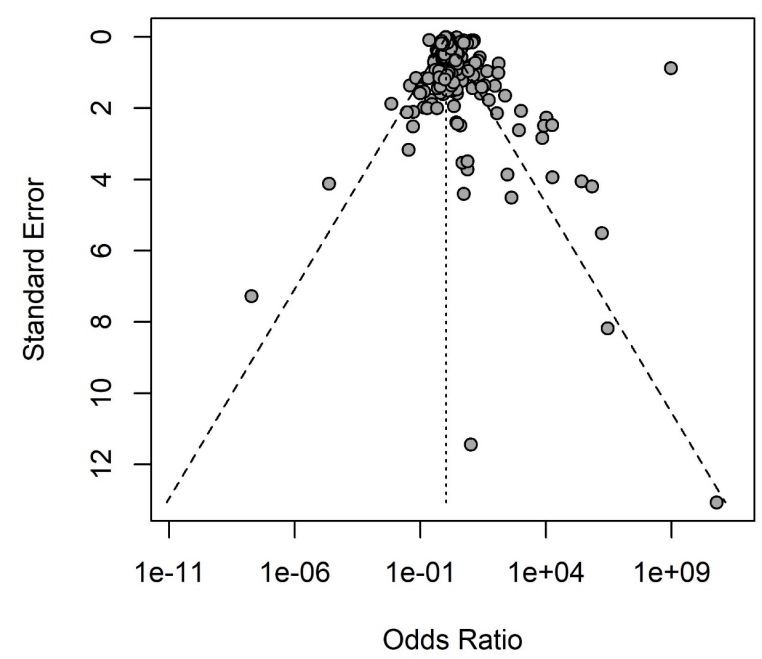

(c) Initiative Available

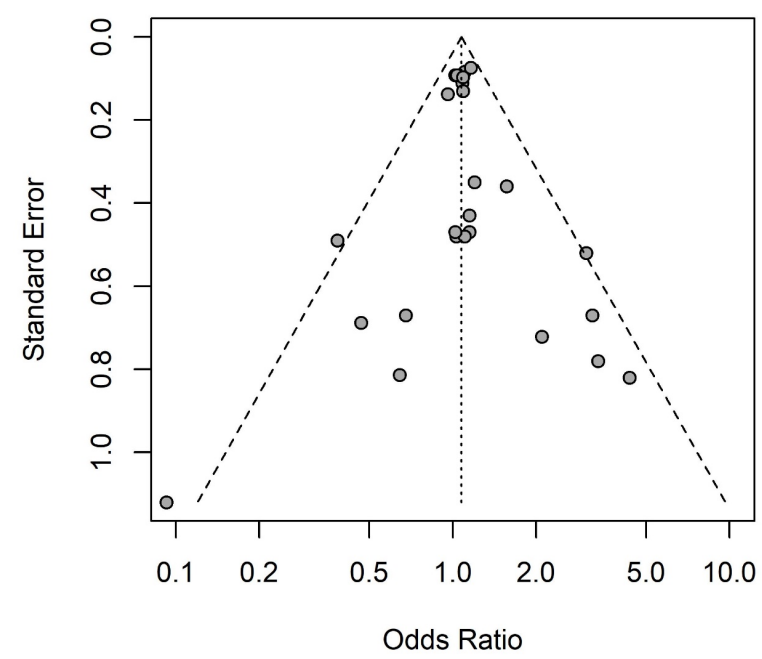

(b) Ideological Distance

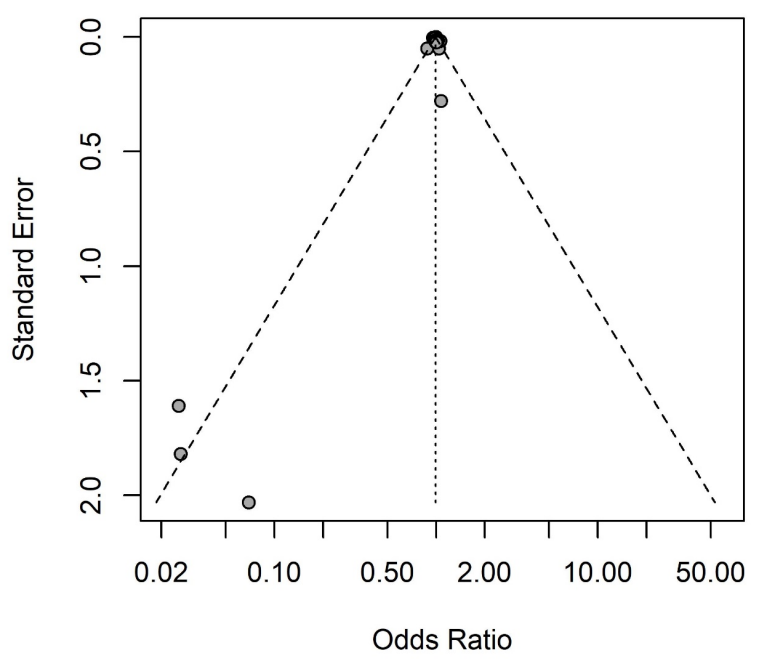

(d) Republican Control of Government

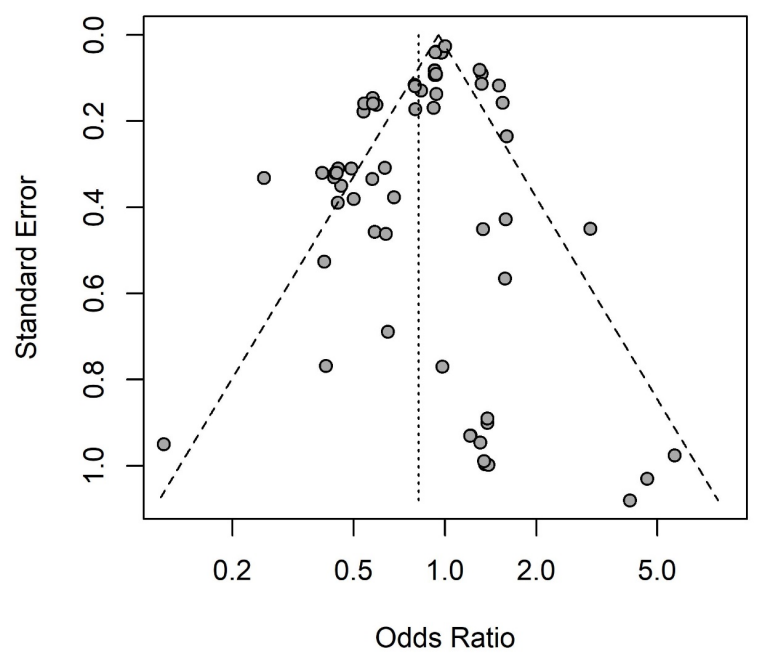

\section{Limitations}

While every effort was made to locate studies that met the inclusion criteria, it is possible that some published studies were missed. This review also does not include the "grey" literature of studies that are available publicly but have not been published in a peer reviewed journal. Additionally, as the funnel plots suggest, that are likely studies that cannot even be located, as 
they have been filed away as unpublishable. The file drawer problem in particularly plagues all efforts to synthesize existing research. Another limitation of this study is that it focuses on the published EHA diffusion literature. While this was a purposeful choice due to the inclusion of a meta-analysis, an increasing number of diffusion studies are departing from this methodological framework. This study is meant to serve as a benchmark for the EHA work that has been done as diffusion scholar expand their methodological toolkit. A final limitation is the focus on diffusion

in the American context. There is a vibrant literature on cross-national diffusion, which could use this study as a guide for how to conduct a similar review.

\section{Discussion and Conclusions}

Taken together, the results of this study demonstrate that policy diffusion research is rich and vibrant, but also suffers from correctable gaps. These gaps include foci of study and the consequent results. While the research on policy diffusion in the American context covers a broad spectrum of policy domains and has good coverage of adoptions since 1960, there are still substantial gaps in policy coverage. Figure 3 should guide researchers toward policies that have not been well represented or studied at all. This leads researchers away from well-trod topics, like morality policies, and towards lower-profile policies like agriculture, local governance, public administration, and technology, among others. The meta-analysis results herein represent what is known from the extant research, but biases resulting from unbalanced policy and temporal coverage, as well as reporting bias, are likely. The identified gaps provide avenues for additional single or small-set policy studies and researchers should avoid working the same ground. Thus, this study systematically captures the profile of convenience sampling in EHA diffusion studies. 
The prevalence of convenience sampling in policy diffusion is not overcome simply by the aggregation of adoption data in datasets like SPID. For example, there is a large cluster of abortion policies present in SPID. In fact, part of the data accumulation process for SPID involved gathering datasets from diffusion researchers, both from published studies and unpublished work. Without a clear sampling frame - perhaps the greatest methodological challenge in diffusion research - any accumulation of data will perpetuate convenience sampling bias. This further substantiates the argument that researchers should pay attention to what policies and domains have already been well examined in diffusion studies when considering new work. It is possible to focus our efforts in systematically developing a body of research that is better balanced in terms of the policies that it studies.

Keeping in mind the limitations of the existing literature, the results of the meta-analysis reveal that there is evidence of general effects across the existing studies for the positive effects of neighbor adoptions and initiative availability and the negative effects of ideological distance, government liberalism, Republican control of government, and divided government. However, there is no evidence of general effects for federal intervention, per capita income, legislative professionalism, and Democratic control of government. Each would be expected to generally increase the likelihood of policy innovation adoption, but the evidence is simply not there. These results are likely driven, at least in part, by where scholars tend to focus their attention, as well as potential publication bias against studies that fail to find external influence of policy adoption.

Additionally, there is heterogeneity in these effects across different types of policies. Regulatory policies appear to be impacted only by internal determinants of adoption such as party control of government and citizen liberalism. Morality policies are strongly affected by 
external influences from contiguous neighbors and ideologically similar states. Finally, the results on governance polices are highly tentative given that they are understudied.

Variation in the motivators of adoption may also be due to temporal changes in the political environment in which they are being measured. Meaning, it is possible that the predictors of diffusion presented by Berry and Berry, as well as the rest of this body of research, are not fixed over time (Mallinson 2019). Recall that Figure 3 demonstrated that most of these studies are conducted on adoptions occurring after 1960. Furthermore, the depth of policy coverage grows over time. Meaning, changes in diffusion predictors due to broader changes within the states and across the federal system could drive the unexpectedly large presence of null effects for many of the predictors included in this study.

The purpose of this systematic review and meta-analysis was to formally examine the research findings of the large, diverse, and long-standing study of policy diffusion in the American states. As diffusion researchers continue to shift away from the dominant analytical paradigm of single-policy case studies towards large-n and mechanistic analyses, it is important to take stock of what we have learned from the large body of EHA studies. Furthermore, moving forward does not strictly speaking mean abandoning this prior approach. It does, however, mean that attention must be paid to the ground that has already been covered and that which requires additional attention. For example, more attention is needed to not only recently adopted innovations, but also older adoptions (particularly pre-1960). Developing single-policy studies that bolster large datasets like SPID and make them more representative across policies and time would improve the generalizability of diffusion research findings. Moreover, this review draws attention understudied or completely ignored policy domains, like agriculture, housing, social 
welfare, local government, and more. As research on policy diffusion moves forward, this study should serve as an important benchmark of the research produced in the last 30 years.

\section{References}

Adam, Christian. 2016. "Simulating policy diffusion through learning: Reducing the risk of false positive conclusions." Journal of Theoretical Politics 28 (3):497-519.

Allen, Mahalley D., Carrie Pettus, and Donald P. Haider-Markel. 2004. "Making the National Local: Specifying the Conditions for National Government Influence on State Policymaking." State Politics \& Policy Quarterly 4 (3):318-344.

Balla, Steven J., and Christopher J. Deering. 2015. "Salience, complexity and state resistance to federal mandates." Journal of Public Policy 35 (03):459-476.

Baumgartner, Frank R., Virginia Gray, and David Lowery. 2009. "Federal Policy Activity and the Mobilization of State Lobbying Organizations." Political Research Quarterly 62 (3):552-567.

Berry, Frances Stokes, and William D. Berry. 1990. "State Lottery Adoptions as Policy Innovations: An Event History Analysis." American Political Science Review 82 (4):395415.

— 2018. "Innovation and Diffusion Models in Policy Research." In Theories of the Policy Process, ed. C. M. Weible and P. Sabatier. New York: West View Press.

Berry, William D., and Brady Baybeck. 2005. "Using Geographic Information Systems to Study Interstate Competition." American Political Science Review 99 (4):505-519.

Berry, William D., Evan J. Ringquist, Richard C. Fording, and Russell L. Hanson. 1998. "Measuring Citizen and Government Ideology in the American States, 1960-93." American Journal of Political Science 42 (1):327-348. 
Boehmke, Frederick J. 2009. "Approaches to Modeling the Adoption and Diffusion of Policies with Multiple Components." State Politics \& Policy Quarterly 9 (2):229-252.

Boehmke, Frederick J., Mark Brockway, Bruce Desmarais, Jeffrey J. Harden, Scott LaCombe, Fridolin Linder, and Hanna Wallach. 2019. "SPID: A New Database for Inferring Public Policy Innovativeness and Diffusion Networks." Policy Studies Journal Forthcoming.

Boehmke, Frederick J., and Paul Skinner. 2012a. "The Determinants of State Policy Innovativeness." In State Politics and Policy Conference. Houston, Texas.

_. 2012b. "State Policy Innovativeness Revisited." State Politics \& Policy Quarterly 12 (3):303-329.

Boushey, Graeme. 2010. Policy Diffusion Dynamics in America. New York, NY: Cambridge University Press.

Bowman, Ann O'M., and Neal D. Woods. 2007. "Strength in Numbers: Why States Join Interstate Compacts." State Politics \& Policy Quarterly 7 (4):347-368.

Butler, Daniel M., Craig Volden, Adam M. Dynes, and Boris Shor. 2017. "Ideology, Learning, and Policy Diffusion: Experimental Evidence." American Journal of Political Science 61 (1):37-49.

Costa, Mia. 2017. "How Responsive are Political Elites? A Meta-Analysis of Experiments on Public Officials." Journal of Experimental Political Science 4 (3):241-254.

Franco, Annie, Neil Malhotra, and Gabor Simonovits. 2014. "Publication bias in the social sciences: Unlocking the file drawer." Science 345 (6203):1502.

Gilardi, Fabrizio. 2012. "Transnational Diffusion: Norms, Ideas, and Policies." In Handbook of International Relations, ed. T. Risse and B. Simmons. Thousand Oaks: SAGE Publications. 
Gilardi, Fabrizio, and Fabio Wasserfallen. 2019. "The politics of policy diffusion." European Journal of Political Research 58 (4):1245-1256.

Graham, Erin R., Charles R. Shipan, and Craig Volden. 2013. "The Diffusion of Policy Diffusion Research in Political Science." British Journal of Political Science 43 (3):673-701.

Gray, Virginia. 1973. "Innovation in the States: A Diffusion Study." American Political Science Review 67 (4):1174-1185.

Grossback, Lawrence J., Sean Nicholson-Crotty, and David A. M. Peterson. 2004. "Ideology and Learning in Policy Diffusion." American Politics Research 32 (5):521-545.

Haider-Markel, Donald P. 2001. "Policy Diffusion as a Geographical Expansion of the Scope of Political Conflict: Same-Sex Marriage Bans in the 1990s." State Politics \& Policy Quarterly 1 (1):5-26.

Hannah, A. Lee, and Daniel J. Mallinson. 2018. "Defiant Innovation: The Adoption of Medical Marijuana Laws in the American States." Policy Studies Journal 46 (2):402-423.

Hartung, Joachim, and Guido Knapp. 2001. "A refined method for the meta-analysis of controlled clinical trials with binary outcome." Statistics in Medicine 20 (24):3875-3889.

Jansa, Joshua M., Eric R. Hansen, and Virginia H. Gray. 2019. "Copy and Paste Lawmaking: Legislative Professionalism and Policy Reinvention in the States." American Politics Research 47 (4):739-767.

Jordan, Marty P., and Matt Grossman. 2017. "The Correlates of State Policy Project v.2.1." ed. I. f. P. P. a. S. R. (IPPSR). East Lansing, MI.

Karch, Andrew. 2007. "Emerging Issues and Future Directions in State Policy Diffusion Research." State Politics \& Policy Quarterly 7 (1):54-80. 
. 2012. "Vertical Diffusion and the Policy-Making Process: The Politics of Embryonic Stem Cell Research." Political Research Quarterly 65 (1):48-61.

Kreitzer, Rebecca J. 2015. "Politics and Morality in State Abortion Policy." State Politics \& Policy Quarterly 15 (1):41-66.

Lau, Richard R., Lee Sigelman, and Ivy Brown Rovner. 2007. "The Effects of Negative Political Campaigns: A Meta-Analytic Reassessment." Journal of Politics 69 (4):1176-1209.

Layman, Geoffrey C., and John C. Green. 2006. "Wars and Rumours of Wars: The Contexts of Cultural Conflict in American Political Behavior." British Journal of Political Science 36 (1):61-89.

Liberati, Alessandro, Douglas G Altman, Jennifer Tetzlaff, Cynthia Mulrow, Peter C Gøtzsche, John P A Ioannidis, Mike Clarke, P J Devereaux, Jos Kleijnen, and David Moher. 2009. "The PRISMA statement for reporting systematic reviews and meta-analyses of studies that evaluate healthcare interventions: explanation and elaboration." BMJ 339.

Linder, Fridolin, Bruce Desmarais, Matthew Burgess, and Eugenia Giraudy. 2018. "Text as Policy: Measuring Policy Similarity through Bill Text Reuse." Policy Studies Journal Forthcoming.

Maggetti, Martino, and Fabrizio Gilardi. 2016. "Problems (and solutions) in the measurement of policy diffusion mechanisms." Journal of Public Policy 36 (01):87-107.

Mallinson, Daniel J. 2016. "Building a Better Speed Trap: Measuring Policy Adoption Speed in the American States." State Politics \& Policy Quarterly 16 (1):98-120.

_ 2019. "Who are Your Neighbors? The Role of Ideology and Decline of Geographic Proximity in the Diffusion of Policy Innovations." Policy Studies Journal Forthcoming. 
_. 2020. "Policy Innovation Adoption across the Diffusion Life Course." Policy Studies Journal Forthcoming.

Martin, Isaac William. 2009. "Proposition 13 Fever: How California's Tax Limitation Spread." The California Journal of Politics \& Policy 1 (1):1-17.

Matisoff, Daniel C. 2008. "The Adoption of State Climate Change Policies and Renewable Portfolio Standards: Regional Diffusion or Internal Determinants?" Review of Policy Research 25 (6):527-546.

McCoy, Edgar. 1940. "Patterns of Diffusion in the United States." American Sociological Review $5(219-227)$.

McLaughlin, Joseph P., Paul Wolfgang, J. Wesley Leckrone, Justin Gollob, Jason Bossie, Jay Jennings, and Michelle J. Atherton. 2010. "The Pennsylvania Policy Database Project: A Model for Comparative Analysis." State Politics \& Policy Quarterly 10 (3):320-336.

Moher, David, Alessandro Liberati, Jennifer Tetzlaff, Douglas G. Altman, and Prisma Group The. 2009. "Preferred Reporting Items for Systematic Reviews and Meta-Analyses: The PRISMA Statement." PLoS Med 6 (7):e1000097.

Mooney, Christopher Z. 2001. The Public Clash of Private Values: The Politics of Morality Policy. New York, NY: Chatham House Publishers.

Mooney, Christopher Z., and Mei-Hsien Lee. 2000. "The Influence of Values on Consensus and Contentious Morality Policy: U.S. Death Penalty Reform, 1952-82." Journal of Politics $62(1): 223-239$.

Mooney, Christopher Z., and Richard G. Schuldt. 2008. "Does Morality Policy Exist? Testing a Basic Assumption." Policy Studies Journal 36 (2):199-218. 
Nicholson-Crotty, Sean. 2009. "The Politics of Diffusion: Public Policy in the American States." Journal of Politics 71 (1):192-205.

Nicholson-Crotty, Sean C., Neal D. Woods, Ann O'M Bowman, and Andrew Karch. 2014. "Policy Innovativeness and Interstate Compacts." Policy Studies Journal 42 (2):305-324.

Pacheco, Julianna. 2012. "The Social Contagion Model: Exploring the Role of Public Opinion on the Diffusion of Antismoking Legislation across the American States." Journal of Politics 74 (1):187-202.

Riverstone-Newell, Lori. 2017. "The Rise of State Preemption Laws in Response to Local Policy Innovation." Publius: The Journal of Federalism 47 (3):403-425.

Savage, Robert L. 1978. "Policy Innovativeness as a Trait of American States." Journal of Politics 40 (1):212-224.

Schwarzer, Guido, James R. Carpenter, and Gerta Rücker. 2015. Meta-Analysis with R. New York: Springer.

Sellers, Mitchell Dylan. 2017. "Gubernatorial use of executive orders: unilateral action and policy adoption." Journal of Public Policy 37 (3):315-339.

Shipan, Charles R., and Craig Volden. 2008. "The Mechanisms of Policy Diffusion." American Journal of Political Science 52 (4):840-857.

Sidik, Kurex, and Jeffrey N. Jonkman. 2002. "A simple confidence interval for meta-analysis." Statistics in Medicine 21 (21):3153-3159.

Smith, Daniel A., and Dustin Fridkin. 2008. "Delegating Direct Democracy: Interparty Legislative Competition and the Adoption of the Initiative in the American States." The American Political Science Review 102 (3):333-350. 
Squire, Peverill. 2012. The Evolution of American Legislatures. Ann Arbor, MI: University of Michigan Press.

—. 2017. "A Squire Index Update." State Politics \& Policy Quarterly 17 (4):361-371.

Tolbert, Caroline J. 2002. "Rethinking Lowi's Constituent Policy: Governance Policy and Direct Democracy." Environment and Planning C: Government and Policy 20 (1):75-93.

Veroniki, Areti Angeliki, Dan Jackson, Wolfgang Viechtbauer, Ralf Bender, Jack Bowden, Guido Knapp, Oliver Kuss, Julian P. T. Higgins, Dean Langan, and Georgia Salanti. 2016. "Methods to estimate the between-study variance and its uncertainty in metaanalysis." Research synthesis methods 7 (1):55-79.

Viechtbauer, Wolfgang. 2010. "Conducting Meta-Analyses in R with the metafor Package." Journal of Statistical Software 36 (3):1-48.

Volden, Craig, Michael M. Ting, and Daniel P. Carpenter. 2008. "A Formal Model of Learning and Policy Diffusion." The American Political Science Review 102 (3):319-332.

Walker, Jack L. 1969. "The Diffusion of Innovations among the American States." American Political Science Review 63 (3):880-899.

—. 1973. "Comment: Problems in Research on the Diffusion of Policy Innovations." American Political Science Review 67 (4):1186-1191.

Welch, Susan, and Kay Thompson. 1980. "The Impact of Federal Incentives on State Policy Innovation." American Journal of Political Science 24 (4):715-729. 